\title{
Pneumonia among children under five in Uganda: symptom recognition and actions taken by caretakers
}

\author{
Doreen Tuhebwe ${ }^{1}$, Elly Tumushabe ${ }^{2}$, Elli Leontsini ${ }^{3}$, Rhoda K Wanyenze ${ }^{1}$
}

1. Makerere University College of Health Sciences, School of Public Health

2. Mukono District Health Office, District Health Office

3. Johns Hopkins Bloomberg School of Public Health

\begin{abstract}
Background: Pneumonia is a leading cause of death among children under five years of age. Pneumonia deaths could be averted if caretakers recognized the danger signs and sought appropriate treatment promptly.

Methods: We interviewed 278 caretakers in Mukono district Uganda, whose under-five children had suffered from probable pneumonia two weeks prior to the evaluation. Through structured questionnaires we assessed caretaker's knowledge about danger signs among under-five children with pneumonia and the actions taken to manage probable pneumonia using descriptive statistics. We also conducted in-depth interviews with caretakers and community health workers.

Results: Lower chest wall in drawing (a pneumonia specific danger sign) was mentioned by only $9.4 \%$ of the caretakers. Among the Integrated Management of Childhood Illnesses (IMCI) standard general danger signs, inability to feed was the most commonly cited danger sign $(37.8 \%)$ followed by incessant vomiting $(10.1 \%)$. No caretaker mentioned all the four standard general danger signs. In terms of actions taken, most caretakers offered drinks $(49.6 \%)$ and traditional herbs $(45.3 \%)$ while, $31.7 \%$ gave antibiotics.

Conclusions: Caretaker's knowledge about danger signs was inadequate in relation to the IMCI guidelines. Caretakers used both modern and traditional forms of treatment to manage pneumonia. Comprehensive interventions geared at increasing symptom recognition and improving health-seeking behavior are needed to reverse this trend.
\end{abstract}

Key words: Pneumonia, Knowledge, Dangers signs, Care seeking, Uganda.

DOI: http://dx.doi.org/10.4314/ahs.v14i4.31

\section{Introduction}

Pneumonia is a leading cause of death among children under five years of age (U5s), causing roughly $1 \bullet 6$ million deaths per year ${ }^{1}$ and is one of the biggest barriers to the attainment of the Millennium Development Goal (MDG) 4 -reduce child mortality by two thirds by 2015. Pneumonia deaths could be averted if caretakers recognized the symptoms and danger signs in children with pneumonia, sought treatment promptly ${ }^{2}$ and offered appropriate home care to the children including adherence to prescription and proper feeding ${ }^{3}$.

\section{Corresponding author:}

Doreen Tuhebwe

Makerere University College of Health Sciences

School of Public Health, Dean's Office

Email: tuhereen@yahoo.com,dtuhebwe@musph. ac.ug
A UNICEF/WHO report that examined the epidemiological evidence on the burden, distribution of pneumonia and the current levels of treatment and prevention globally, showed that only about 1 in every 5 caretakers know the danger signs of pneumonia. Also 1 in every $5 \mathrm{knew}$ the two tell-tale or indicative symptoms of pneumonia: fast breathing and difficult breathing. In addition, only about half of the children sick with pneumonia receive appropriate medical care and, less than 20 per cent of children with pneumonia receive antibiotics ${ }^{2}$.

Recognizing the symptoms of pneumonia is the first step in reducing deaths among children under five and caretakers play a critical role in recognizing pneumonia symptoms, its danger signs and in immediately seeking appropriate care for their sick children. Studies show that failure to recognize signs and symptoms of childhood illness prevents or delays care seeking ${ }^{4-5}$. Furthermore, the health belief model states that when symptoms are perceived as a threat to life, individuals will take action ${ }^{6}$. 
After recognizing symptoms, the second step is for the HSD was selected because it is the largest HSD in Mucaretaker to take action including seeking appropriate kono district and is composed of both rural and urban medical care for a child with suspected pneumonia. populations.

Appropriate care, as defined by WHO and UNICEF,

includes consultation with providers that can correct- In 2011, pneumonia was the leading cause of death ly diagnose and treat pneumonia, such as facility and among U5s in Mukono district, with a case fatality rate formally trained community based health providers ${ }^{2}$. of 5\% (District HMIS 2010/2011). Integrated CommuHowever, other supportive home based care such as nity Case Management of Childhood illnesses (ICCM) increased fluids, appropriate infant feeding, and child was introduced in Mukono district two years prior warming by caretakers are important ${ }^{7}$. All these actions to this evaluation. The ICCM programme includes case are critical elements to prevent child deaths ${ }^{8}$.

The Integrated Management of Childhood Illnesses (IMCI) guidelines, define general and pneumonia specific danger signs which require that a sick child be managed quickly and referred immediately after the pre-referral treatment'. These general danger signs include: inability to feed, incessant vomiting, lethargy/ unconsciousness and convulsions while the pneumonia specific danger signs include lower chest wall in drawing and stridor ${ }^{10}$.

In order to encourage more appropriate involvement of families in pneumonia management, pneumoni control programs require information on caretakers' knowledge about pneumonia among U5s, the prevailing care seeking and home based care practices. This is critical in the design of evidence-based intervention to promote family involvement in appropriate care seeking and supportive home care.

This evaluation aimed to assess caretaker's knowledge about danger signs among U5s with pneumonia and the actions taken in the management of pneumonia in $\mathrm{Mu}$ kono district, Uganda.

\section{Methods}

Evaluation setting

Mukono district is one of the districts implementing the Village Health Team (VHT) strategy in Uganda. VHTs are a cadre introduced by the Ministry of Health to mobilize communities and strengthen health service delivery at the household level ${ }^{12}$.

Between July and August 2012, we conducted an evaluation using a cross sectional design in two sub counties of Mukono North health sub district (HSD) in Uganda; Nama a typically rural area and Mukono Town council an urban area. Mukono North HSD is 22 kilometers from the capital city Kampala with a population of 39248 U5s (Mukono district profile). Mukono North

trained to identify, and assess childhood illnesses in-

che

given a kit with pre-packaged medicines and diagnostic

supplies to manage these common illnesses in order to

reduce delays in accessing appropriate care ${ }^{12}$, however

the functionality has not been evaluated.

\section{Sample size calculation}

We estimated a sample size of 278 caretakers using the Kish Leslie 1965 formulae with the assumptions that; $86 \%$ of U5s receive cough treatment at home ${ }^{13}$ as proxy for the percentage of caretakers who provide some form of home care for pneumonia; a $5 \%$ precision and a 1.5 design effect.

\section{Sampling procedure}

Two of the four parishes in Mukono town council and three out of the six in Nama Sub County were randomly selected using a table of random numbers. Both urban and rural parishes were sampled to provide better representation of the district. From a total of 50 villages that were eligible for sampling in all the 5 parishes, 15 villages were selected.

Systematic sampling was used to select households with the eligible respondent who was a caretaker of a child below five years of age. A caretaker was defined as an adult who was found to be in custody or guardianship of the U5 at the time of the evaluation. If several adults were present at the time, the one with the closest relationship to the child was selected due to the decision making power that close relatives hold.

The total number of households in each of the selected villages was obtained from the Local Chairperson (LC1) and the sampling interval was calculated for each village through dividing the total number of households per village by the number of households targeted for inclusion in each village. The LC-1's household was the starting point for sampling in each village.
To identify eligible respondents, caretakers were asked if the child or any of the children in the household had suffered from cough and fast breathing (probable pneumonia) locally defined as "Lubyamira" two weeks prior to that day. The caretakers, who affirmed to this, were enrolled if they consented to participate. If a household had no child who had suffered from cough and fast breathing two weeks prior to the evaluation, the next nearest household within the same direction was selected.

\section{Data collection}

Quantitative data was collected using a pretested structured questionnaire which was developed based on a modified optimal care seeking framework (OCSF) by Baume, with themes on symptom recognition, appropriate home care and monitoring, and treatment at a health facility ${ }^{14}$.

The steps in the framework represent critical decision points at which performance of optimal behavior maximizes the likelihood that the illness will be resolved. For example, if a caretaker gives the correct antibiotics, in the correct dose with appropriate supportive care like breast feeding and keeping the child warm, the child is likely to recover, and it is not necessary to proceed with the other steps in the model. Conversely, failure to perform optimal behaviors at a given step can have serious consequences.

The questionnaire was administered to the caretakers in the local language (Luganda) by trained research assistants. Responses elicited included; most common childhood illnesses, knowledge about danger signs in children and actions taken by the caretaker when a child presents with cough and fast breathing. The responses were unprompted and caretakers were asked to mention all the options that they knew, followed with the prompt "anything else?"

After the quantitative survey, we conducted in-depth and key informant interviews to explain some of the findings observed. The reasons for the observed practices among caretakers were elicited through in-depth interviews with caretakers whose children had suffered from cough and fast breathing two weeks prior to the evaluation. Ten in-depth interviews were conducted inNama. Key informant interviews were conducted with five VHTs from each of the five rural villages that were randomly selected from Nama. The key informant interviews focused on the VHTs' experiences managing children with pneumonia, and their perceptions of the actions taken by the caretakers. No key informant interviews were conducted with VHTs from the urban area since no VHTs had been trained in the urban setting.

\section{Ethics}

Written informed consent was sought from each caretaker prior to the structured and in-depth interviews.

This evaluation was conducted as part of the $\mathrm{Mu}$ kono district monitoring and evaluation activities to inform adjustments in the district interventions. Hence we did not obtain approval from the institutional review board but rather approval from the Mukono District Health Office. The evaluation was conducted under supervision of Makerere University School of Public Health

\section{Data analysis}

Questionnaires were entered in EPI data and analyzed in STATA version ${ }^{10}$. The unit of analysis was the U5 caretaker. Univariate analysis was done to present measures of knowledge about danger signs and actions taken including home management and seeking health care outside the home.

To assess caretaker's knowledge, the danger signs reported by the caretakers were compared to the standard IMCI guidelines and frequencies were used to present measures of knowledge and the actions taken by caretakers.

Qualitative data was analyzed by themes, emerging among caretakers and VHT members.

\section{Results}

\section{Rocio-demographic characteristics}

Majority of the caretakers $(96.4 \%$; $268 / 278)$ were female and $82.4 \%(229 / 268)$ were mothers of the children. Most of the caretakers were aged 21-35years, $45.0 \%(125 / 278)$ had attained secondaty level education and $76.3 \%(212 / 278)$ were married (Table 1). 


\begin{tabular}{|c|c|c|}
\hline VARIABLE & FREQUENCY $=278$ & PERCENTAGE $(\%)$ \\
\hline $\begin{array}{l}\text { Sex } \\
\text { Male }\end{array}$ & 10 & $\begin{array}{l}3.6 \\
0.64\end{array}$ \\
\hline Female & 268 & 96.4 \\
\hline \multicolumn{3}{|c|}{ Relations with U5 } \\
\hline & 10 & 3.6 \\
\hline Mother & 229 & 82.4 \\
\hline Other relative & 39 & 14.0 \\
\hline \multicolumn{3}{|c|}{ Age of caretakers } \\
\hline 15-20 years & 37 & \\
\hline & 190 & 68.3 \\
\hline $\begin{array}{l}36-50 \\
56-70\end{array}$ & $\begin{array}{l}35 \\
12\end{array}$ & $\begin{array}{l}12.6 \\
4.3\end{array}$ \\
\hline Do not know & 4 & 1.4 \\
\hline \multicolumn{3}{|c|}{ Education level } \\
\hline & 26 & 9.3 \\
\hline Primary & 119 & 42.8 \\
\hline Sccondary & 125 & 45.0 \\
\hline Tertiary & 8 & 2.9 \\
\hline \multicolumn{3}{|l|}{ Marital status } \\
\hline & 17 & 6.1 \\
\hline Married & 212 & 76.3 \\
\hline $\begin{array}{l}\text { Separated } \\
\text { Widowed }\end{array}$ & $\begin{array}{l}36 \\
13\end{array}$ & $\begin{array}{l}12.9 \\
4.7\end{array}$ \\
\hline \multicolumn{3}{|c|}{ Occupation of caretaker } \\
\hline Employed & 29 & \\
\hline Unemployed & & 36.7 \\
\hline $\begin{array}{l}\text { Trading } \\
\text { Farming }\end{array}$ & 79 & $\begin{array}{l}28.4 \\
24.5\end{array}$ \\
\hline
\end{tabular}

Knowledge about danger signs among children with Among the IMCI standard general danger signs, inabilpneumonia. ity to feed was the most commonly cited $(37.8 \%)$ folLower chest wall in drawing(a pneumonia specific dan- lowed by incessant vomiting (10.1\%) (Table 2). ger sign) was mentioned by only $9.4 \%$ of the caretakers.

Table 2: Danger signs among children under five suffering from pneumonia mentioned by caretakers

\begin{tabular}{lcc}
$\begin{array}{l}\text { Danger sign } \\
\text { Pneumonia specific } \\
\text { Lower chest wall in-drawing }\end{array}$ & Frequency $(\mathbf{n}=\mathbf{2 7 8 )}$ & Percentage \% \\
\cline { 2 - 3 } Difficult breathing & 26 & 9.35 \\
& 22 & 7.91 \\
General danger signs & & \\
Severe weakness & 181 & 65.11 \\
Inability to feed & 105 & 37.77 \\
Incessant vomiting & 28 & 10.07 \\
High fever & 23 & 8.27 \\
Convulsions & 18 & 6.47 \\
Unconsciousness & 14 & 5.04 \\
& & \\
Do not & 36 & 12.95 \\
know any & 15 & \\
danger sign & & 5.01 \\
Others $=$ red eyes, dehydration, & & Multiple responses were given \\
diarrhea &
\end{tabular}

No caretaker mentioned all the four standard general Caretakers' practices in the management of children danger signs. Many caretakers (65.1\%) mentioned se- under five years of age with probable pneumonia

vere weakness, high fever $(8.3 \%)$ and difficult breath- About the actions taken when a child presents with ing $(7.9 \%)$ as danger signs, although these are not listed cough and fast breathing, most caretakers mentioned among the IMCI pneumonia danger signs. giving drinks $(49.6 \% ; 138 / 278)$ and various traditional Caretakers from the urban areas were more knowledge- herbs $(45.3 \% ; 126 / 278)$, followed by seeking care at a able about danger signs compared to caretakers from health facility/from a health care worker. Approximatethe rural areas: $14.4 \%$ of urban caretakers mentioned ly one third (31.7\%) of the caretakers said they give lower chest wall in drawing compared to $6.7 \%$ of rural antibiotics (Table 3) while some mentioned the names caretakers. Inability to feed was mentioned by $44.3 \%$ of of the drugs such as Amoxicillin and Ampicillin.

urban caretakers compared to $33.9 \%$ of rural caretak- Multiple responses were given slightly more caretakers

(46.1\%) from the rural villages mentioned giving herbs compared to $44.3 \%$ from the urban villages.

Table 3: Care practices mentioned by caretakers of children under five suffering from

Pne umonia

\begin{tabular}{lcc}
\hline Home based care practices & Frequency $(\mathbf{n}=\mathbf{2 7 8})$ & Proportion reporting (\%) \\
\hline Give drinks & 138 & 49.64 \\
Give traditional herbs & 126 & 45.32 \\
Take child to the health & 103 & 37.05 \\
worker & & \\
Give antibiotics & 48 & 31.65 \\
Give fruits & 31 & 14.75 \\
Give pain killers & 31 & 11.15 \\
Tepid sponging & 26 & 11.15 \\
Child warming & 18 & 9.35 \\
Breast feeding & 10 & 6.47 \\
Give raw eggs & & 3.60 \\
\hline
\end{tabular}

Give raw eggs

Multiple responses were given

During the in-depth interviews, we identified that many Among the other 7 caretakers, 5 used other drugs like

caretakers use traditional forms of treatment instead of painkillers, which they procured from drug shops, with and in addition to conventional medicine. no provider consultation and only two said they visited In addition to the low use of antibiotics, there was wide a health worker as the first action. From the quantitaspread use of traditional forms of treatment, such as tive interviews with caretakers, $44.2 \%(123 / 278)$ knew herbs to manage pneumonia. Three out of the 10 care- about the existence of VHTs. None of the caretakers takers who participated in the in-depth interviews said in the in-depth interviews had ever visited a VHT when they gave their children local remedies as the first ac- their children were ill and one caretaker from an urban tion. "When I saw that the child was coughing and breathing village said "we do not know the VHTs, they are not active". heavily, I knew it was pneumonia/Lubyamira, so I got lemon, mixed with garlic and added egg yolk, and then I gave the child to Qualitative interviews with the VHTs revealed sevdrink". When asked if the child got better, the caretaker eral challenges especially the lack of medical supplies. said "after two days the cbild was not getting better, so I went to Whereas the VHTs had been trained, they had not been the local private clinic and asked for herbal syrup which I gave given supplies to diagnose and treat sick children. One for three days because I trust herbal remedies, but the child also VHT from a rural village said "I can only tell caretakers to started getting temperature, then I went back to the same clinic go to the government health center since I do not have the drugs... and they gave me Ampicilin, and I saw improvement after four we were promised drugs, but they bave not been brought". days". When asked which medicine made the child bet- The caretakers also mentioned challenges in seeking ter, she said "I think it is Ampicilin because it is only care at health facilities, including long waiting time and after using it, that I really saw improvement" (26- year drug stock outs. When the caretakers were asked where old mother, rural).

they get antibiotics from, two mentioned private clinics 
(at a cost) while the rest mentioned both private and by caretakers is important as it can negatively impact on public facilities. However, those who mentioned public the care seeking behavior.

facilities said they faced challenges in trying to access

the drugs due to long waiting time "the government bealth center has drugs but we wait for long since the drugs are free, but sometimes they get finished and there are only malaria drugs" (32 year old mother, rural).

Caretakers also cited stock out of antibiotics and other drugs, requiring them to go to private facilities. However, they also noted that the antibiotics are expensive at the private clinics and some said that they were unable to afford them "we just buy the drugs from private clinics and they are expensive, so I have never used antibiotics on my child I just go buy Vitamin C, pain killers and congh reliefs and the cbild gets better" (24 year old mother, urban).

One of the caretakers also noted that they did not need to have a prescription when purchasing drugs such as painkillers, syrups and antibiotics from the drug shops and private clinics.

Some of the reasons for the use of herbs that were cited by caretakers were the remedy being inexpensive, while the reasons for the use of antibiotics included trust in the health worker. One caretaker, a 40 year old mothe from an urban village said "cbildren are complicated, I cannot just give them anything, I go to the health worker and I tell them how the child has been then they know best what to give, I do not give anything else".

\section{Discussion}

This evaluation assessed knowledge and actions tak- Step 2: Appropriate home care and monitoring en by caretakers of under-five children with probable All the caretakers reported carrying out at least on

pneumonia. The results show inadequate knowledge home based care practice, which concurs with findabout danger signs a IMCI guidelines.

There was also wide spread use of traditional forms of treatment to manage pneumonia and antibiotic use, not necessarily by prescription.

Caretakers were not seeking help from VHTs as expected from the programs in place, because the VHT system was not fully functional; for example training of VHTs in the urban setting had not yet been done. Thus it is not surprising that the caretakers were not aware of the existence of the VHT. Additionally, the trained VHT did not always have the required supplies as reported in the qualitative interviews. Caretakers also reported lack of medicines in health facilities among the challenges they faced. Whereas this study did not objectively assess availability of drugs in the facility, this perception
The results are discussed using three themes from the OCSF by Baume; recognition of signs, appropriate home care and monitoring and treatment at the health facility

\section{1: Recognition of signs:}

Over half; $67.6 \%$ of the caretakers mentioned pneumonia as one of the childhood illnesses which shows that many caretakers knew that pneumonia was a common childhood illness. This is important since perception he caretakers ${ }^{15}$

Although caretakers knew some danger signs, improvement is needed since the caretakers were not able to mention the danger signs as outlined in the IMCI guidelines 8

Inadequate knowledge and perceptions about dange signs have been noted in other studies and is a maor concern because it may compromise health seeking behavior ${ }^{5}$. The health belief model shows that if symptoms are perceived as a threat (dangers signs), in dividuals take action ${ }^{6}$. However, a correct action taken (such as seeking care from the VHT) in this community tions since this system was not fully functional, with the Vitios. ings that health care in developing countries occurs at home ${ }^{7}$.The majority of the practices mentioned were related to feeding (fruits, drinks, and food), which can be beneficial but not sufficient for improvement of health outcomes for children with pneumoni if appropriate diagnosis and timely antibiotics are not administered by trained providers.

Even when caretakers accessed antibiotics, some did so without a prescription from a trained provider due to gaps in the regulatory mechanisms which make it possible to procure antibiotics without prescription from drug shops and private clinics in Uganda ${ }^{16}$. Some of the caretakers who went to health facilities also did so after trying other remedies and self-medication with inappropriate drugs or antibiotics. This process when protracted may result in delays in seeking care. may not have necessarily led to the desired interven-
Other than low access to antibiotics and seeking of care from trained health workers, the use of other useful home support measures such as child warming, breast feeding and tepid sponging, was also very low, hence the need to promote an entire package of importan home management and health care seeking practices ${ }^{8}$.

\section{Step 3: Treatment at the health facility}

Since the district had a non-functional system for comwas a gap in effectively linking the caretakers to the health facilities. This, among other reasons, may explain why the VHTs were never visited and the use of herb. remedies as the first action of care for the child.

Lack of the required supplies at the VHT level and at health facilities as well as other quality issues (e.g. long waiting time) also compromise the trust in the health system. Community education and mobilization effort should thus be accompanied by improvements in the quality of care at the VHT and facility levels ${ }^{17}$.

\section{Limitations}

This evaluation had some limitations. Assessing caretakers of U5s with probable pneumonia two weeks prior to the evaluation excluded those whose children had had several episodes but out of our time bracket. However restricting the inclusion to caretakers that had recently had this experience would reduce challenge with recall. Secondly, the care seeking questions in the quantitative survey were general and not specific to the actions taken at the last probable pneumonia episode which makes appropriate and timely care seeking difficult to assess in a complete manner. In addition, classification of fast breathing and danger signs such as lowe chest wall in drawing and lethargy were not objectively defined. Nevertheless, the evaluation provides useful information for program improvement in relation to symptom recognition and care seeking.

\section{Conclusion}

This evaluation highlights the challenges in care seeking for pneumonia in a district of Uganda, starting with inadequate knowledge about danger signs among children with pneumonia, insufficient home management practices and, potential for treatment seeking delays along the process. The gaps in the first-line community management system at the VHT level and perceived lack of medicines at the facility level may also exacerbate the poor health seeking behaviors. Comprehensive interventions geared at increasing symptom recogni-

(a)

African Health Sciences Vol 14 Issue 4, December 2014 ion, improving health seeking behavior and the quality are needed to reverse this trend.

\section{Acknowledgements}

We thank the study participants for the data that generated this information, the Mukono District Health Office staff members for field support and research assistants for the data collection. Special thanks go to African Field Epidemiology Network (AFENET) for funding this evaluation.

The work was supported by Grant Number 5R24TW008886 supported by OGAC, NIH and HRSA Its contents are solely the responsibility of the authors and do not necessarily represent the official views of the supporting offices.

\section{Conflict of interest}

We declare no conflict of interest.

\section{References}

1. Black RE, Cousens S, Johnson HL, Lawn JE, Rudan , Bassani DG, et al. Global, regional, and national causes of child mortality in 2008: a systematic analysis. Lan cet. 2010 Jun 5;375(9730):1969-1987.

2. UNICEF/WHO. Pneumonia the forgotten killer of children. Geneva: The United Nations Children's Fund World Health Organization 2006.

3. Rudan I, Boschi-Pinto C, Biloglav Z, Mulholland $\mathrm{K}$, Campbell H. Epidemiology and etiology of childhood pneumonia. Bull World Health Organ. 2008 May;86(5):408-416

4. Chompolola A, Macwan'gi, M. Caretakers' Experiences with Sick Children in Luapula Province: Implications for Child Survival Interventions in Zambia. Medical Journal of Zambia. 2009;35(2)

5. Irimu G, Nduati RW, Wafula E, Lenja J. Community understanding of pneumonia in Kenya. Afr Health Sci. 2008 Jun;8(2):103-107.

6. Rosenstock IM. Why people use bealth services. Milbank. Mem Fund Q. 1966 Jul;44(3):Suppl:94-127.

7. WHO/UNICEF. Countdown to 2015 decade Report 2000-2010: taking stock of maternal, newborn and child survival. 20Avenue Appia, 1211 Geneva 27; Switzerand: World Health Organisation and United Nations International Child Emergency Fund 2010.

8. WHO. IMCI, Integrated management of childhood illnesses; Model chapter for textbooks. Geneva: World Health Organization2005.

9. WHO. Integrated Managment of Childhood Illnesses;IMCI fact sheet 2:World Health Organisaion2006.

4

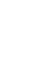

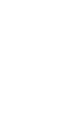


10. WHO. Model Chapter for Textbooks - IMCI - Integrated Management of Childhood Illness.: World Health Organisation2001.

11. MOH. VHT Strategy and Operationsl Guidelines. Kampala: Ministry of Health, Uganda: Health Education and Promotion Division2010.

12. MOH. ICCM; Integrated Community Case Managment of Childhood Malaria, Pneumonia and Diarrhoea. Kampala, Uganda: United Nations International Child Emergency Fund, World Health Oganisation, Ministry of Health Uganda2010 May 2010.

13. Kallander K, Nsungwa-Sabiiti J, Balyeku A, Pariyo G, Tomson G, Peterson S. Home and community management of acute respiratory infections in children in eight Ugandan districts. Ann Trop Paediatr. 2005 Dec;25(4):283-291.

14. Baume C. A Guide to Research on Care-seeking for Childhood Malaria. Arlington, Virginia: Published by the Support for Analysis and Research in Africa (SARA) Project and the Basic Support for Institutionalizing Child Survival Project (BASICS II) for the United States Agency for International Development.2002 April.

15. Kallander K, Tomson G, Nsabagasani X, Sabiiti JN, Pariyo G, Peterson S. Can community health workers and caretakers recognise pneumonia in children? Experiences from western Uganda. Trans $\mathrm{R}$ Soc Trop Med Hyg. 2006 Oct;100(10):956-963.

16.Ogwal-Okeng JW, Obua C, Waako P, Aupont O, Ross-Degnan D. A comparison of prescribing practices between public and private sector physicians in Uganda. East Afr Med J. 2004 Feb;Suppl:S12-16.

17. Arifeen SE, Bryce J, Gouws E, Baqui AH, Black RE, Hoque DM, et al. Quality of care for under-fives in first-level health facilities in one district of Bangladesh. Bull World Health Organ. 2005 Apr;83(4):260-267. 